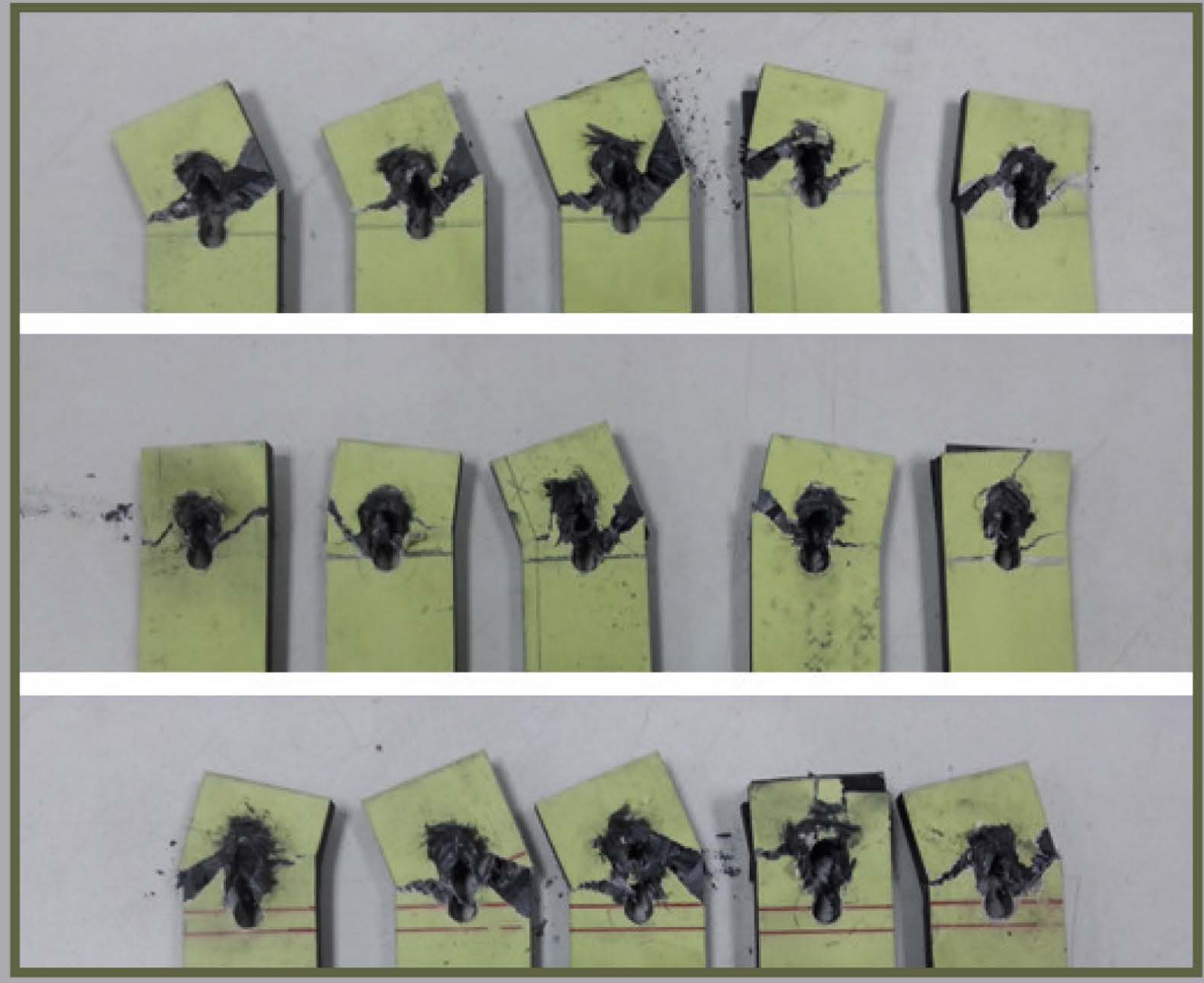

HOLE-MAKING AND

DRILLING TECHNOLOGY

FOR COMPOSITES

ADVANTAGES, LIMITATIONS AND POTENTIAL 
Hole-Making and Drilling Technology for Composites 
This page intentionally left blank 
Woodhead Publishing Series in Composites Science and Engineering

\section{Hole-Making and Drilling Technology for Composites}

Advantages, Limitations and Potential

Edited by

A.B. Abdullah

S.M. Sapuan 
Woodhead Publishing is an imprint of Elsevier

The Officers' Mess Business Centre, Royston Road, Duxford, CB22 4QH, United Kingdom

50 Hampshire Street, 5th Floor, Cambridge, MA 02139, United States

The Boulevard, Langford Lane, Kidlington, OX5 1GB, United Kingdom

() 2019 Elsevier Ltd. All rights reserved.

No part of this publication may be reproduced or transmitted in any form or by any means, electronic or mechanical, including photocopying, recording, or any information storage and retrieval system, without permission in writing from the publisher. Details on how to seek permission, further information about the Publisher's permissions policies and our arrangements with organizations such as the Copyright Clearance Center and the Copyright Licensing Agency, can be found at our website: www.elsevier.com/permissions.

This book and the individual contributions contained in it are protected under copyright by the Publisher (other than as may be noted herein).

\section{Notices}

Knowledge and best practice in this field are constantly changing. As new research and experience broaden our understanding, changes in research methods, professional practices, or medical treatment may become necessary.

Practitioners and researchers must always rely on their own experience and knowledge in evaluating and using any information, methods, compounds, or experiments described herein. In using such information or methods they should be mindful of their own safety and the safety of others, including parties for whom they have a professional responsibility.

To the fullest extent of the law, neither the Publisher nor the authors, contributors, or editors, assume any liability for any injury and/or damage to persons or property as a matter of products liability, negligence or otherwise, or from any use or operation of any methods, products, instructions, or ideas contained in the material herein.

\section{Library of Congress Cataloging-in-Publication Data}

A catalog record for this book is available from the Library of Congress

\section{British Library Cataloguing-in-Publication Data}

A catalogue record for this book is available from the British Library

ISBN: 978-0-08-102397-6

For information on all Woodhead publications

visit our website at https://www.elsevier.com/books-and-journals

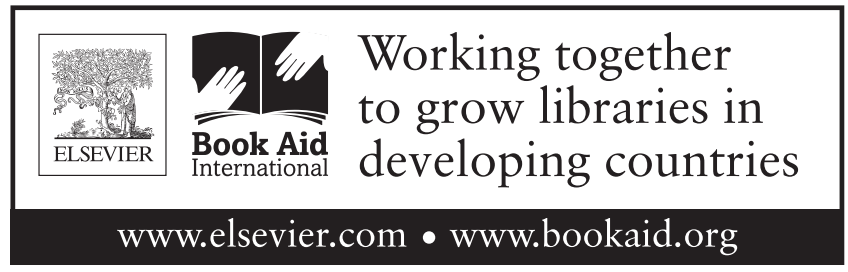

Publisher: Matthew Deans

Acquisition Editor: Gwen Jones

Editorial Project Manager: Joshua Mearns

Production Project Manager: Joy Christel Neumarin Honest Thangiah

Cover Designer: Miles Hitchen

Typeset by SPi Global, India 


\section{Contents}

List of contributors $\quad$ ix

1 Review of hole-making technology for composites 1

M.S. Abdullah, A.B. Abdullah and Z. Samad

1.1 Introduction $\quad \mathbf{1}$

1.2 Hole-making for composite laminates $\quad \mathbf{1}$

$\begin{array}{ll}1.3 \text { Conclusions } & \mathbf{1 1}\end{array}$

Acknowledgments $\quad 12$

$\begin{array}{ll}\text { References } & 12\end{array}$

2 Defects in holes-making on composite panels: A review on delamination

M.S. Abdullah, A.B. Abdullah and Z. Samad

$\begin{array}{lll}2.1 & \text { Introduction } & 17\end{array}$

$\begin{array}{ll}2.2 \text { Delamination } & \mathbf{1 7}\end{array}$

2.3 Delamination mechanism $\quad \mathbf{1 8}$

2.4 Causes of delamination $\quad 19$

2.5 Delamination measurement $\quad 24$

$\begin{array}{lll}2.6 & \text { Conclusions } & \mathbf{2 7}\end{array}$

Acknowledgments $\quad \mathbf{2 8}$

References $\quad \mathbf{2 8}$

$\begin{array}{ll}\text { Further reading } & \mathbf{3 0}\end{array}$

3 Structural integrity assessment of a composite joint: A review 31

M.S. Abdullah, A.B. Abdullah and Z. Samad

3.1 Introduction $\quad \mathbf{3 1}$

3.2 Types of joints $\quad 32$

3.3 Standard test procedure $\quad \mathbf{3 4}$

3.4 Failure mode $\quad \mathbf{4 2}$

3.5 Conclusions $\quad \mathbf{4 2}$

Acknowledgment $\quad 43$

$\begin{array}{ll}\text { References } & 43\end{array}$

$\begin{array}{ll}\text { Further reading } & 46\end{array}$ 
4 Drilling of fiber-reinforced composites: An innovative tool design

M.H. Hassan and J. Abdullah

$\begin{array}{lll}4.1 & \text { Introduction } & 47\end{array}$

4.2 Types of FRC laminates materials in aircraft manufacturing $\quad \mathbf{4 8}$

4.3 Hole-making procedures in drilling FRC laminate materials $\quad 50$

4.4 Drill tool material and tool design geometry $\mathbf{5 2}$

4.5 Influence of tool design on hole quality $\quad \mathbf{5 7}$

$\begin{array}{lll}4.6 & \text { Summary } & \mathbf{5 9}\end{array}$

Acknowledgments $\quad \mathbf{6 0}$

$\begin{array}{ll}\text { References } & 60\end{array}$

$5 \quad$ Drilling of composite laminates using a special tool point geometry $\quad 63$

K. Debnath

5.1 Introduction $\quad \mathbf{6 3}$

5.2 Materials and methods $\quad \mathbf{6 4}$

$\begin{array}{lll}5.3 & \text { Results and discussion } & \mathbf{6 7}\end{array}$

$\begin{array}{lll}5.4 & \text { Conclusions } & \mathbf{7 4}\end{array}$

$\begin{array}{ll}\text { References } & 75\end{array}$

6 Application of ultrasonic-assisted machining process for making hole in composite laminates

K. Debnath

6.1 Introduction

6.2 Ultrasonic machining: Process principle $\quad \mathbf{7 9}$

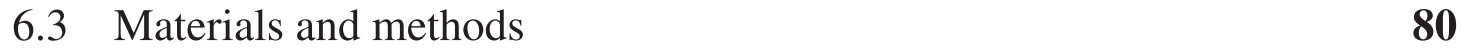

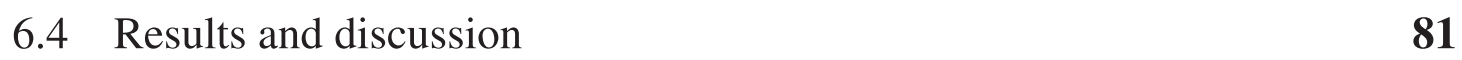

$\begin{array}{ll}6.5 \text { Conclusions } & 84\end{array}$

$\begin{array}{lr}\text { References } & \mathbf{8 6}\end{array}$

7 Laser drilling of composite material: A review 89

K.F. Tamrin, N.A. Sheikh and S.M. Sapuan

$\begin{array}{lll}7.1 & \text { Introduction } & \mathbf{8 9}\end{array}$

7.2 General methods of laser drilling $\quad 90$

\begin{tabular}{ll}
7.3 & Formation of tapered hole \\
\hline
\end{tabular}

7.4 Laser drilling methods to suppress delamination
and thermal defects in composites

7.5 Ultrashort laser pulses for composite drilling 94

$\begin{array}{lll}7.6 & \text { Effects of underwater laser drilling } & 97\end{array}$

$\begin{array}{lll}7.7 & \text { Conclusions } & 97\end{array}$

$\begin{array}{lr}\text { Acknowledgment } & 97\end{array}$

$\begin{array}{ll}\text { References } & 98\end{array}$

8 Drilling of glass fiber reinforced plastics (GFRPs): An experimental investigation and finite element study

S. Prakash, P.V. Siva Teja, J. Lilly Mercy

and A.B. Abdullah

8.1 Introduction

8.2 Experimental procedures 
8.3 Finite element study

103

$\begin{array}{lll}8.4 & \text { Results and discussion } & \mathbf{1 0 7}\end{array}$

$\begin{array}{lll}\text { 8.5 Conclusions } & \mathbf{1 0 7}\end{array}$

Acknowledgments $\quad 113$

$\begin{array}{ll}\text { References } & 113\end{array}$

9 Precision punching: A new method in hole-making on composite panels

A.B. Abdullah, H.Y. Chan, M.S.M. Zain, N. Ishak and Z. Samad

9.1 Introduction

115

9.2 Principles of the punching process $\quad \mathbf{1 1 6}$

$\begin{array}{lll}9.3 & \text { Materials and methods } & \mathbf{1 1 6}\end{array}$

9.4 Results and discussion $\quad \mathbf{1 2 2}$

$\begin{array}{ll}9.5 \text { Conclusion } & 131\end{array}$

Acknowledgment 132

References 132

10 Single-shot titanium/carbon fiber reinforced composites/aluminum stacks holes drilling

M.H. Hassan and J. Abdullah

10.1 Introduction 135

10.2 Current practice in drilling of stacked material (multistep process) $\mathbf{1 3 6}$

10.3 Hole quality issues in single-shot drilling process of stacked material

10.4 Benefits and limitations of single-shot drilling process $\mathbf{1 4 2}$

10.5 Tool strategies for drilling of stacked material $\mathbf{1 4 3}$

$\begin{array}{ll}10.6 \text { Summary } & 146\end{array}$

Acknowledgments $\quad 146$

References 146

11 Sustainability issues in hole-making technologies: Current practices and challenges

A.B. Abdullah, S.M. Sapuan and Z. Samad

11.1 Introduction

149

$\begin{array}{ll}\text { 11.2 Sustainability issues } & \mathbf{1 5 0}\end{array}$

11.3 Conclusions and challenges in hole-making technologies $\mathbf{1 5 5}$

$\begin{array}{ll}\text { Acknowledgment } & 157\end{array}$

$\begin{array}{ll}\text { References } & 157\end{array}$

12 Machinability studies in drilling carbon fiber reinforced composites 161

A. Krishnamoorthy, S. Prakash, J. Lilly Mercy and S. Ramesh

$\begin{array}{lll}12.1 & \text { Introduction } & 161\end{array}$

12.2 Effects of machining on composites $\quad \mathbf{1 6 2}$

$\begin{array}{lll}12.3 & \text { Fabrication of composites } & \mathbf{1 6 4}\end{array}$

12.4 Mathematical formulation $\quad \mathbf{1 6 6}$

$\begin{array}{lll}12.5 & \text { Thrust force } & \mathbf{1 6 7}\end{array}$

$\begin{array}{lr}12.6 & \mathbf{1 6 9}\end{array}$ 
12.7 Thrust force for various cutting velocities and feed rates

12.8 Regression analysis

12.9 Validation

12.10 Conclusion

References

Further reading

13 Burr assessment of punched holes on Al/CFRP/Al-stacked panel by profile measurement technique

N. Ishak, A.B. Abdullah and Z. Samad

13.1 Introduction

13.2 Methodology

13.3 Results and discussion

13.4 Conclusions and recommendations for future work Acknowledgment

References

14 Electro-discharge drilling of metal matrix composites

A. Singh, S. Kachhap and R. Kumar

14.1 Introduction

14.2 Scheme of experiments

14.3 Phase I: Experimental study

195

14.4 Phase II: Response surface method

14.5 Conclusions

References

15 Quality and performance assessments of drilling and punching in the hole-making process of a composite panel: A comparative study

S. Norisam and A.B. Abdullah

15.1 Introduction

15.2 Hole quality

15.3 Performance

15.4 Methodology

15.5 Result and discussion

15.6 Conclusions and future works

Acknowledgment

References

Further reading 


\section{List of contributors}

A.B. Abdullah School of Mechanical Engineering, Universiti Sains Malaysia, Nibong Tebal, Malaysia

J. Abdullah School of Mechanical Engineering, Engineering Campus, Universiti Sains Malaysia, Nibong Tebal, Malaysia

M.S. Abdullah School of Mechanical Engineering, Universiti Sains Malaysia, Nibong Tebal, Malaysia

H.Y. Chan School of Mechanical Engineering, Universiti Sains Malaysia, Nibong Tebal, Malaysia

K. Debnath Department of Mechanical Engineering, National Institute of Technology Meghalaya, Shillong, India

M.H. Hassan School of Mechanical Engineering, Engineering Campus, Universiti Sains Malaysia, Nibong Tebal, Malaysia

N. Ishak School of Mechanical Engineering, Universiti Sains Malaysia, Nibong Tebal, Malaysia

S. Kachhap National Institute of Technology Patna, Patna, India

A. Krishnamoorthy School of Mechanical Engineering, Sathyabama Institute of Science and Technology, Chennai, India

R. Kumar Indian Institute of Technology Roorkee, Roorkee, India

J. Lilly Mercy School of Mechanical Engineering, Sathyabama Institute of Science and Technology, Chennai, India

S. Norisam School of Mechanical Engineering, Universiti Sains Malaysia, Nibong Tebal, Malaysia

S. Prakash School of Mechanical Engineering, Sathyabama Institute of Science and Technology, Chennai, India 
S. Ramesh Department of Mechanical Engineering, KCG College of Technology, Chennai, India

Z. Samad School of Mechanical Engineering, Universiti Sains Malaysia, Nibong Tebal, Malaysia

S.M. Sapuan Department of Mechanical and Manufacturing Engineering, Universiti Putra Malaysia, Serdang, Malaysia

N.A. Sheikh Department of Mechanical Engineering, International Islamic University, Islamabad, Pakistan

A. Singh National Institute of Technology Patna, Patna, India

K.F. Tamrin Department of Mechanical and Manufacturing Engineering, Universiti Malaysia Sarawak (UNIMAS), Kota Samarahan, Malaysia

P.V. Siva Teja Department of Mechanical Engineering, Dhanekula Institute of Engineering and Technology, Vijayawada, India

M.S.M. Zain School of Mechanical Engineering, Universiti Sains Malaysia, Nibong Tebal, Malaysia 


\title{
Laser drilling of composite material: A review
}

\author{
K.F. Tamrin ${ }^{*}$, N.A. Sheikh ${ }^{\dagger}$, S.M. Sapuan ${ }^{*}$
}

${ }^{*}$ Department of Mechanical and Manufacturing Engineering, Universiti Malaysia Sarawak (UNIMAS), Kota Samarahan, Malaysia, ${ }^{\dagger}$ Department of Mechanical Engineering, International Islamic University, Islamabad, Pakistan, ${ }^{\ddagger}$ Department of Mechanical and Manufacturing Engineering, Universiti Putra Malaysia, Serdang, Malaysia

\subsection{Introduction}

Acceptance of carbon fiber-reinforced plastics (CFRPs) composites in many commercial and industrial applications has increased owing to its excellent strength-to-weight ratio especially offered by the laminates. For matrices such as polyetheretherketone (PEEK), a thermoplastic resin is preferred owing to its higher toughness and resistance to abrasive wear compared to thermoset resin [1]. Laminates of PEEK-CF also exhibit stability at relatively higher service temperatures of $150^{\circ} \mathrm{C}$ as the thermoplastic matrix offers better mechanical properties and resistance to chemically resistant working environment [2].

In the past decade, several new materials and manufacturing processes have been proposed and developed. A new class of structural materials, ceramic matrix composites (CMC), has emerged with the carbon fiber-based reinforcements along with silicon carbide matrices ( $\mathrm{C} / \mathrm{SiC}$ or $\mathrm{C} / \mathrm{C}-\mathrm{SiC}$ composites). $\mathrm{C} / \mathrm{SiC}$ composites have several features such as having reinforcements of relatively shorter lengths, cheap polymer precursors, and liquid phase processes; these features reduce their costs by almost one order of magnitude. The application of first-generation $\mathrm{C} / \mathrm{SiC}$ composites was primarily in space [3] and military [4] applications. Owing to the better properties and thermal stability, several other applications of these composites have been realized. For instance, due to low thermal expansion and better tribological properties, brake disks, pads, clutches, calibration plates, and furnace charging devices use $\mathrm{C} / \mathrm{SiC}[5,6]$.

Lasers have long been employed in several machining and fabrication processes. Metals have been usual target materials for their applications; however, recently laser applications for dissimilar materials have been extensively studied. For instance, joining/welding of dissimilar materials [7-9], ablation [10-12], cutting [13-15], and drilling $[16,17]$ have exhibited successful use. Laser processing has been of particular benefits in areas where high precision is required. Critical areas/parts such as turbine blades and jet engine combustion chambers require cooling and laser-drilled holes provide the necessary boundary layer film cooling [18, 19]. A single engine for applications in defense industries can have several hundred thousands of such cooling holes/passages which require precise machining. Other applications of such precise need of manufacturing processes are highly compact miniaturized electronic 
packages, injector holes for IC engines [20, 21], drip-irrigation pipes, surgical tools $[22,23]$, etc. Almost all such applications need holes be drilled precisely and laser application is best suited for such applications.

Further to its ability of precise control, the noncontact nature of the process is also hugely beneficial compared to conventional tools for drilling. For instance, in the case of composites, avoiding direct contact between the tool and the workpiece removes the delamination caused by thrust force and vibration effects which may be caused otherwise $[24,25]$. Fine bore-sized hole with diameter up to $25 \mu \mathrm{m}$ is possible. In fact, the smallest size of bore depends on the beam spot diameter of laser, while the large sized holes $(>0.5 \mathrm{~mm}$ diameter) can be drilled by peripheral removal of material at the bore outline. In laser drilling, the prime mechanism of material removal is using high-intensity stationary laser beam with the focus on the surface where material is to be removed. At sufficient power densities of laser the material can get heated, melted and subsequently ejected in either liquid and/or vapor phase.

Given the mechanism of material removal is through phase change, industrial laser processing can lead to higher magnitude of heat affected zone (HAZ) as the polymer matrices have lower vaporization temperatures as well as thermal conductivity compared to carbon fibers. It is noted that the heat affected zone causing thermal damage to unidirectional and/or crossply composites laminates is proportional to the specific laser energy (a ratio of laser power to scanning speed) [26].

It can be concluded from the above discussion that the laser processing for composite materials is intricate. Primarily the composites and its constituents have poor thermal conductivities, heat capacities, and low vaporization temperatures, thus the energy imparted during laser processing can severely damage the material.

\subsection{General methods of laser drilling}

\subsubsection{Laser percussion drilling}

Two major methods/approaches are employed for laser drilling processes. Fig. 7.1 depicts the trepanning and percussion drilling processes. In order to avoid contamination to the laser optics from ejected debris, assisted gas is utilized. The assisted gas supplied coaxially also helps in material removal during the process. Basically a single pulse of laser can remove a narrow (less than $1 \mathrm{~mm}$ ) hole of material in thin (less than $1 \mathrm{~mm}$ ) specimens. This single pulse drilling is extended to perform percussion drilling to drill larger holes in thicker specimens (more than $1 \mathrm{~mm}$ ) (Fig. 7.1A). In industrial laser drilling, usually high-power densities are supplied during a single pulse to irradiate enough energy which can vaporize the material in a pulse. In percussion drilling, a sequence of such short bursts/pulses (duration between $10^{-12}$ and $10^{-3} \mathrm{~s}$ ) is imparted on the base material at a relatively longer time period $\left(\sim 10^{-2} \mathrm{~s}\right)$. This directed at a spot forms a larger and through hole. During each pulse, a certain amount of material at a certain depth is removed, thus a sequence of bursts can remove large chuck. For percussion drilling purposes, pulsed Nd:YAG laser is the best choice owing to higher energy per pulse [27, 28].

The physical processes involved in general laser drilling, especially percussion drilling of metal, are schematically shown in Fig. 7.2. Three stages can be identified in 


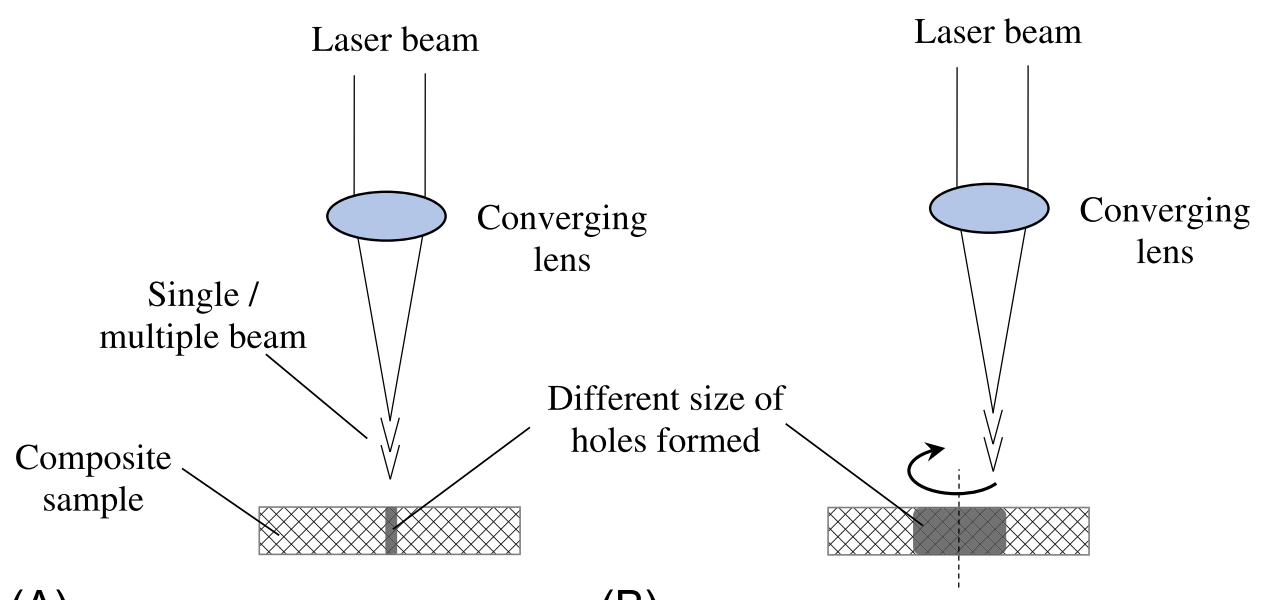

(A)

(B)

Fig. 7.1 General methods of laser drilling: (A) percussion [27] and (B) trepanning [20].

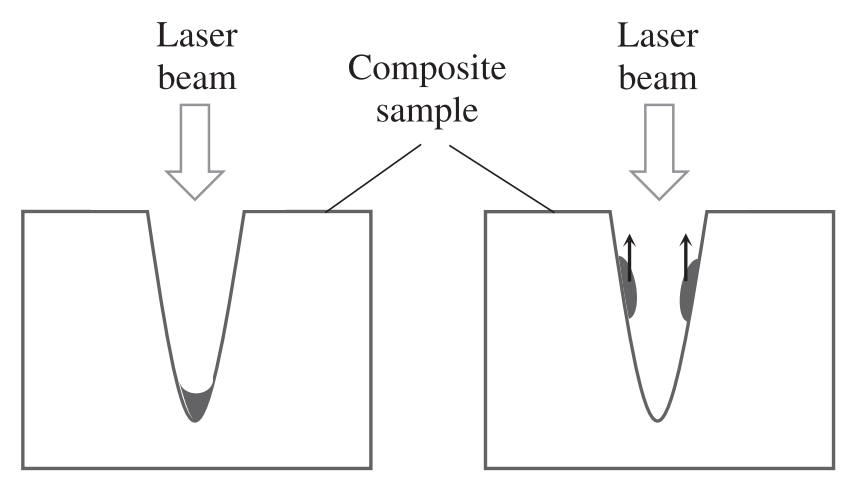

(A)
(B)

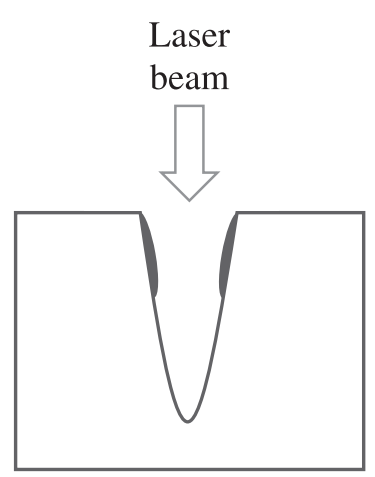

(C)

Fig. 7.2 Physical processes during percussion laser drilling: (A) melt pool formation, (B) splashing out of molten material, and (C) formation of recast layer [29].

the percussion drilling process. At the start, at the target surface a thin region of molten material is created by absorbing laser energy imparted through pulse (Fig. 7.2A). As the meltpool temperature increases and approaches vaporization temperature, the second phase starts with the expansion of vapors evaporating from the surface leading to the splashing stage. During splashing stage, the melt pool is pushed out radially due to the recoil pressure (Fig. 7.2B). The mechanism involved during this meltpool expulsion is the favorable molten layer, pressure gradients at the surface of the molten layer grows larger than the inward surface tension, the net force expels molten material from the hole [29]. However, during this transport some portion of melted material may stick to the walls of the hole and resolidify (Fig. 7.2C). While for the composite base materials the process becomes much more intricate due to different thermo-kinetic properties of the constituents of composite material.

\subsubsection{Laser trepanning drilling}

For much wider holes (less than $3 \mathrm{~mm}$ ) in thicker substrates (less than $10 \mathrm{~mm}$ ), trepanning (Fig. 7.1B) process is employed. This involves drilling a contour on the plate by using a series of overlapping holes at the periphery. This process can be performed by either translating the workpiece or refocusing optics. This process resembles the 
contour/path cutting process and allows laser usage in either continuous wave $(\mathrm{CW})$ or pulsed mode. $\mathrm{CO}_{2}$ and $\mathrm{Nd}$ :YAG lasers are most commonly used in trepanning.

The tremendous variety offered in the laser trepanning drilling has helped industrial process to achieve repeatable, high precision larger holes at high speeds. For instance, helical trepanning involves focusing the beam at the center of the hole while revolving the substrate around the perimeter. This allows gradual deepening of hole at each cycle of rotation [30]. Focal point can also be changed sometimes during the rotation cycles in such process.

\subsection{Formation of tapered hole}

The formation of holes during laser drilling has typically tapered cross-sectional view as depicted in Fig. 7.2. The hole diameter reduces as the depth of hole increases, thus forming a tapered wall. Such topography is formed owing to the fact that in the normal setting the laser is irradiated normal to the surface. As the depth of holes increases there is reduction in hole size primarily due to a relatively lesser contribution of heat energy due to lower reflection from the machined sides of the hole. As the depth increases the laser beam is absorbed by carbon fiber instead of reflection from metals. This results in lowering of the laser energy intensity at the hole bottom, thereby decreasing the hole size [31]. Moreover, the plasma due to assisted gas can absorb some of the laser energy and contribute toward tapering shape [32]. In CFRP the heat generated through laser is rather quickly conducted to the surrounding material owing to relatively higher thermal conductivity. This results in lowering of temperature at the zone sides than at the zone center of the machined area. Thus, the ablation of the central zone precedes the rest due to fast build-up at the central zone by incident pulses. The profile of the incident beam is also a factor that contributes to the tapered shaped holes. Gaussian distribution of the energy intensity results in higher intensity at the center resulting in the removal of more material at the center than sides. Possibility to remove tapering is proposed by Salama et al. [33] either by tilting the sample or offsetting the laser beam. For instance, for drilling cooling fluid holes in turbine blades, holes are drilled at an angle to the surface to remove taper [34].

\subsection{Laser drilling methods to suppress delamination and thermal defects in composites}

Considering the percussion drilling process and its associated mechanism, the use of a pulsed Nd:YAG laser has demonstrated damage to matrix even at the slightest of energy impart despite extensive modulation in the pulse rate, energy intensity, and repetition rate [35]. Several defects such as discontinuities at the interfaces between layers have been found by Rodden et al. [36]. These layers contained differently orientated fibers which resultantly increased delaminative effects [36]. Another study indicated poor-quality effects in drilling microholes using $1 \mathrm{kHz}$ mode-locked Ti:sapphire laser 
(120 fs pulses at $795 \mathrm{~nm}$ ) on PEEK-CF. Defects such as waviness and irregular shapes were observed due to the preferential ablation of the polymer [37].

The CFRP drilling through laser trepanning showed numerous drawbacks with only success while drilling very thin laminates of up to $0.3 \mathrm{~mm}$ with a proper selection of drilling parameters. With laminates having thickness larger than $1 \mathrm{~mm}$, ejection of ablated material from the hole in a single groove becomes difficult due to high aspect ratio between cutting depth and kerf width. This results in an extended thermal damage of the groove along the circumferential direction with irregularly shaped edges. Moreover, the rough edges trap the incident beam through multiple internal reflections preventing the progression of the cut. Localization of energy in the trap of the groove in the presence of high thermal conductivity of fibers cause extended degradation of the matrix.

To circumvent the heat trapping in the groove in single-ring trepanning, Li et al. [38] demonstrated a strategy involving multiple rings thereby widening the cut kerf. This results in effective material removal and restricts heat accumulations (Fig. 7.3). $\mathrm{Li}$ et al. also showed that by performing multi-ring strategy the material can be removed layer by layer with a wide kerf (ring width). This not only facilitates better material ejection from the central zone where beam/material interacts, but it also reduces the shielding of incident laser beam by the plume generated. Upper surface of the substrate is set as the first focal plane, at the beginning of drill. In the multi-ring, focal plane moves downwards by an increment of $0.25 \mathrm{~mm}$ for each set of 100 passes. The drilling starts from the outer diameter of the hole by creating a trench to block the additional energy input generated by the internal rings from transferring along the fibers to the surrounding bulk material. The experiments demonstrated that a series of trepanning passes could be performed while reaching the hole depth of $6 \mathrm{~mm}$ for the cut through. Multi-ring showed a relatively lower HAZ with size of $50 \mu \mathrm{m}$ using a nanosecond pulsed UV laser. The drilling was performed at significantly higher scanning speed $(800 \mathrm{~mm} / \mathrm{s})$. It is noted that the short pulse and high scanning speed help in reducing HAZ. Moreover, this method can be employed for both trepanning [20, 33, 38] and percussion drilling [20].

For very small hole diameter $(\sim 100 \mu \mathrm{m})$ on a relatively thick laminate $(\sim 2.5 \mathrm{~mm})$ another study by Romoli et al. [20] used a removal mechanism based on double ring instead of percussion drilling. The advantage of internal ring ablation allows

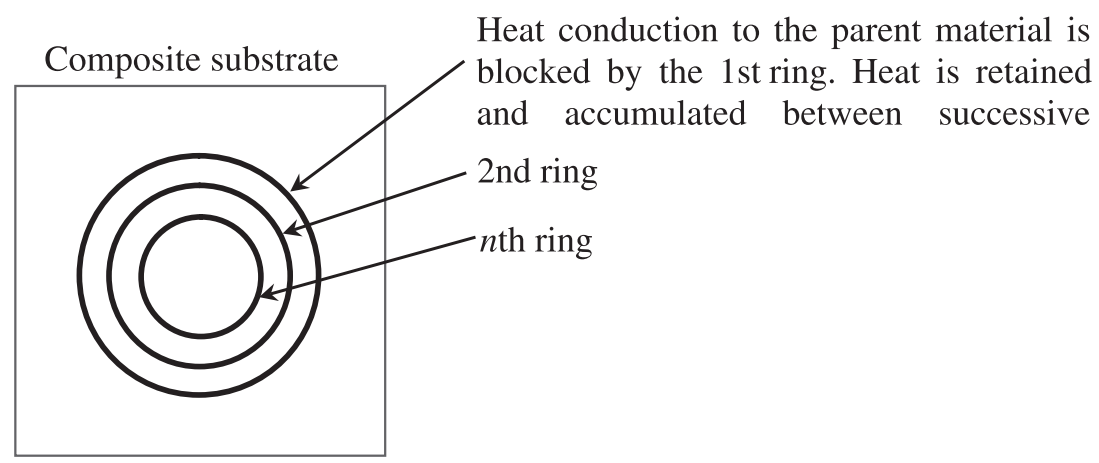

Fig. 7.3 An innovative laser drilling technique by using multiple rings to reduce heat accumulation [38]. 
deeper penetration of beam in the substrate. Resultantly, the conical topology of the inner surface of hole can be decreased compared to conventional percussion drilling.

\subsection{Ultrashort laser pulses for composite drilling}

Previously lasers with pulse duration ranging in the order of $100 \mu$ s were employed in laser drilling operations to achieve target material temperature in excess of boiling point. However, for longer and small diameter holes ultrashort pulse duration laser is required due to large aspect ratio. In such ultrashort laser pulses the duration of pulse is of the order of picoseconds $\left(10^{-12} \mathrm{~s}\right)$. In such short pulses the ultrashort laser offers a relatively broad spectrum with high peak intensity and the frequency of repetition can be high as well.

At short wavelengths and pulse durations, laser beam-material interaction takes place at a shallow absorption depth. This helps in drafting small features and drill miniature holes of good quality, especially with pulse duration of the order of $100 \mathrm{~ns}$ or less. With this configuration, the peak power can be ranging above $1 \mathrm{~kW}$. It is pertinent to mention that the dominant transport mechanism in laser drilling process can be purely thermal or photochemical. This depends primarily on the wavelength of the laser beam. In the UV range (shorter wavelengths), higher photon energy can be obtained leading to photochemical mechanism. While in infrared range (longer wavelengths), the dominant mechanism is thermal reaction due to low photon energy. In short-range/UV lasers, two types of laser-material interaction take place. One is photochemical ablation and other is the photothermal ablation. Critical breaking energy for bond depends on a threshold of photon energy or critical wavelength. For instance, the average binding energy of $347 \mathrm{~kJ} / \mathrm{mol}$ is present between one $\mathrm{C}-\mathrm{C}$ bond and for $\mathrm{C}-\mathrm{H}$ bond the binding energy is $414 \mathrm{~kJ} / \mathrm{mol}$. To achieve such energies, required photon energies range between 3.6014 and $4.2967 \mathrm{eV}$, or in terms of wavelength such energy can be achieved between 344 and $288 \mathrm{~nm}$ [39].

The shortest wavelengths and pulse durations can be generated by excimer lasers but its application is generally restricted to poor beam quality and often need to be used in combination with mask projection. In several materials including unidirectional laminates, HAZ of as low as $5-30 \mu \mathrm{m}$ can be observed at this range of wavelength and pulse durations [20]. In this range the photons carry very high energy and can overcome bond energy easily while ensuring smooth edges. However, such processing parameters are combined with low repetition frequency resulting in slower material removal rates and thus not preferred in industrial processes.

\subsubsection{Nanosecond laser pulses}

Nanosecond laser pulses, though not considered as ultrafast laser pulses, are used for the purpose of drilling by some authors [40-42]. For drilling in GFRP and CFRP, Yalukova et al. [39] used three different types of laser wavelengths (see Table 7.1). 
Table 7.1 Laser specifications in drilling of GFRP and CFRP using nanosecond lasers [39]

\begin{tabular}{|c|c|c|c|c|c|}
\hline$\lambda(\mathbf{n m})$ & $\begin{array}{l}\text { Pulse } \\
\text { energy } \\
(\mathbf{m J})\end{array}$ & $\begin{array}{l}\text { Average } \\
\text { power }(W)\end{array}$ & $\begin{array}{l}\text { Spot } \\
\text { diameter } \\
(\mu \mathbf{m})\end{array}$ & $\begin{array}{l}\text { Irradiance } \\
\left(\mathrm{kW} / \mathrm{cm}^{2}\right)\end{array}$ & $\begin{array}{l}\text { Photon } \\
\text { energy }(\mathrm{eV})\end{array}$ \\
\hline IR: 1064 & 4.8 & 4.8 & 60 & 170 & 1.165 \\
\hline Green: 532 & 2.8 & 2.8 & 40 & 223 & 2.331 \\
\hline UV: 266 & 0.5 & 0.5 & 20 & 159 & 4.662 \\
\hline
\end{tabular}

Epoxy was used as thermoset material for the experiments. This can be influenced to various extents by the wavelengths in infrared $(\lambda=1064 \mathrm{~nm})$, visible $(\lambda=532 \mathrm{~nm})$, and ultraviolet regions $(\lambda=266 \mathrm{~nm})$. At infrared region, experiments indicate epoxy burning and thermal damage of glass and carbon fibers. On the other hand, by irradiating both composites in visible range the influence of thermal breakage was significantly reduced as no visible signs of burning were observed. However, some cracks appeared in epoxy matrix as it is greatly influenced by thermal and/or mechanical stress. While for UV range beam, better quality holes were drilled owing to better photochemical decomposition of the epoxy matrix and can overcome the bond energy for both bonds ( $\mathrm{C}-\mathrm{C}$ and $\mathrm{C}-\mathrm{H}$ covalent bonds). Moreover, minimum burring of edges of holes was observed in UV range while maximum thermal deterioration is seen at infrared range.

\subsubsection{Picosecond laser pulses}

For materials with high hardness, picosecond laser offers a viable machining tool [43-45]. For composites such as CFRP, which includes constituents of varying physical and thermal properties, laser machining is quite challenging as it results in extended HAZ. For such cases, ultrashort pulsed picosecond laser makes machining possible with improved quality.

In C/SiC composites, Liu et al. [46] and Zhang et al. [47] investigated the influence of processing parameters using picosecond laser. The processing parameters include energy intensity, scanning speed, width and spacing of helical line, and machining time, while surface morphology of machined microholes were analyzed. It was noted that two parameters, that is, energy density and feed speed had the most influence on the drilled microholes in terms of its shape and depth. The morphology of the drilled hole in terms of exit side cross section is compared with the entry side. Taper in the holes were observed to increase with machining time but upon a threshold value of machining time the taper size seemed to stay unchanged. This was linked with the depleted laser energy by the debris and the sputtering from the microhole in the presence of plasma at prolonged durations of time. The influence of scanning speed was apparent on the hole depth which increased up to $700 \mu \mathrm{m}$ with the increase in speed. However, afterwards the depth of hole did not increase owing to the reduction in laser energy in the presence of large debris/nanoparticles and shielded plasma. Moreover, debris primarily of $\mathrm{C}, \mathrm{Si}$, and $\mathrm{O}$ was observed on the machined surfaces. The bonding 
between $\mathrm{Si}-\mathrm{C}$ in the matrix was resultantly changed to $\mathrm{Si}-\mathrm{O}$ bond after the machining process. It is estimated that around two photons of photoenergy were necessary to break the covalent bond in $\mathrm{C} / \mathrm{SiC}$ composites. The resultant crystalline structure is distorted and the formation of free atoms is observed after bond rupture. At this energy, the free atom plasma ejected from the sides of the holes.

In other study, $\mathrm{Li}$ et al. [30] investigated the effect of picosecond laser irradiance on different $\mathrm{SiC} / \mathrm{SiC}$ composites and demonstrated that good-quality circular holes can be formed through helical line modes. It was observed that $10 \mathrm{~W}$ was the most suitable processing power of laser owing to the considerations of material oxidation and geometrical size of holes. For larger size holes, higher quantities of debris and nanoparticles were observed in the machining zone at processing power ranging between 4 and $12 \mathrm{~W}$. At low range of power, larger quantities of debris were observed to be attached to the walls of machined hole. It was primarily due to the incomplete oxidation of material for lack of laser energy. The resultant pressures at this power setting were not enough to eject the debris from the hole, resultantly particles accumulated at the walls of hole and adsorb more and more incident energy of laser thereby effecting machining process considerably. Furthermore, pits and pores of varying sizes were seen in and on the sides of the hole which reduced the oxidation resistance of composites thereby causing more damage.

In another experimental study involving multiple-ring material removal in CFRP drilling employing $400 \mathrm{~W}$ picoseconds laser, Salama et al. [33] found that HAZ and ablation depths decrease with reduction in laser power and increase in the scanning speed. Evidently less than $25 \mu \mathrm{m}$ HAZ were observed on the top side of 6-mm-diameter hole. The procedure was completed at a scanning speed of $2 \mathrm{~m} / \mathrm{s}$ in a sample with $6 \mathrm{~mm}$ thickness. On the whole no apparent marks of HAZ were seen other than on the top surface. This observed HAZ at the entrance of hole was measured to be much smaller than the previously reported results employing similar laser setups [38].

In a separate study, Wang et al. [48] used picosecond laser for machining circular and square holes. It was noted that depth of holes reduced with an increase in the laser scanning speed, while hole diameter showed unappreciable change. The edges and bottom sides of the circular and square holes were flooded with small particles. Moreover, due to composite heterogeneity the bottom of square holes was found to be cone-shaped cell with waviness.

\subsubsection{Femtosecond laser pulses}

Femtosecond laser pulses were investigated for machining in CFRP by Moreno et al. [37]. Extensive analysis revealed that the shape and dimensions of filling material (either carbon black or carbon fiber) caused geometrical deformations of drilled holes. Relatively speaking, carbon black filled polymers were observed to have better hole topology when drilled using femtosecond intense pulsed lasers. On the other hand, irregular shape, waviness, and other defects were observed in microholes drilled in CFRPs. It was concluded that fiber dimensions and preferential ablation of the polymer was the main reasons. 


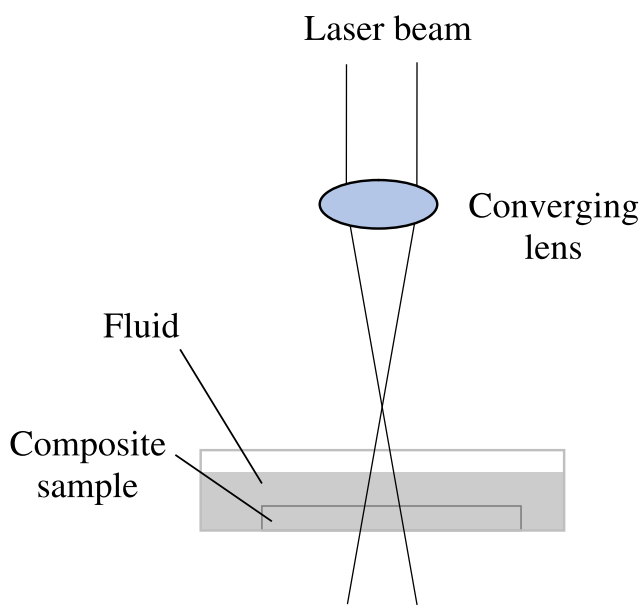

(A)

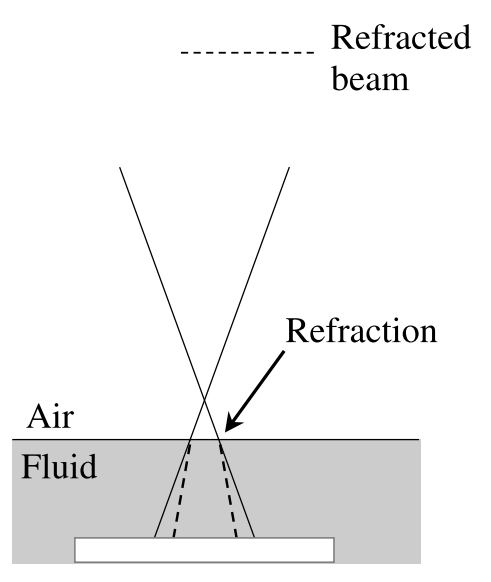

(B)

Fig. 7.4 (A) Schematic diagram of underwater laser drilling, and (B) its effect on beam spot size due to refraction at air-fluid interface [49].

\subsection{Effects of underwater laser drilling}

Numerous studies involving materials undergoing laser machining, while submerged in water have been extensively studied such as, aluminum [49], steel [50], silicon carbide [51], and alumina [52]. However, to the best of the knowledge of authors, no such study is found in any of the publically available literature for underwater laser drilling of metallic and/or nonmetallic composites. Fig. 7.4 schematically shows the underwater laser drilling process on a material and the influence of water as media on the beam. Water being denser medium, refraction at the air-fluid interface causes reduction in spot size compared to air. In addition to beam size variation, the influence of stagnant and moving fluid also needs consideration. In a stagnant medium, the debris/particles formed in the process can partially or fully block the beam causing hole defects, while the moving fluid, in parallel or angled flow directions, can remove the debris/particles due to turbulence at the interface. But this resultantly causes irregular beam spot size.

\subsection{Conclusions}

In this chapter, percussion, trepanning, and multiple-ring trepanning methods used in laser drilling are discussed. To mitigate the unwanted drilling-induced delamination, the use of ultrashort laser pulses for composite material drilling and their effects on hole properties are reviewed. This chapter provides a basis for future research in underwater laser drilling of composites.

\section{Acknowledgment}

This work was supported by Universiti Malaysia Sarawak (UNIMAS) under Grant F02/ SpSTG/1567/2017. 


\section{References}

[1] J. Flöck, K. Friedrich, Q. Yuan, On the friction and wear behaviour of PAN-and pitchcarbon fiber reinforced PEEK composites, Wear 225 (1999) 304-311.

[2] F. Mata, V. Gaitonde, S. Karnik, J.P. Davim, Influence of cutting conditions on machinability aspects of PEEK, PEEK CF 30 and PEEK GF 30 composites using PCD tools, J. Mater. Process. Technol. 209 (2009) 1980-1987.

[3] N.P. Padture, Advanced structural ceramics in aerospace propulsion, Nat. Mater. 15 (2016) 804.

[4] M. Grujicic, B. Pandurangan, B. d'Entremont, The role of adhesive in the ballistic/structural performance of ceramic/polymer-matrix composite hybrid armor, Mater. Des. 41 (2012) 380-393.

[5] Z. Stadler, K. Krnel, T. Kosmač, Friction and wear of sintered metallic brake linings on a C/C-SiC composite brake disc, Wear 265 (2008) 278-285.

[6] W. Krenkel, F. Berndt, C/C-SiC composites for space applications and advanced friction systems, Mater. Sci. Eng. A 412 (2005) 177-181.

[7] K. Tamrin, Y. Nukman, N. Sheikh, M. Harizam, Determination of optimum parameters using grey relational analysis for multi-performance characteristics in CO 2 laser joining of dissimilar materials, Opt. Lasers Eng. 57 (2014) 40-47.

[8] K. Tamrin, Y. Nukman, S. Zakariyah, Laser lap joining of dissimilar materials: a review of factors affecting joint strength, Mater. Manuf. Process. 28 (2013) 857-871.

[9] K. Tamrin, Y. Nukman, N. Sheikh, Laser spot welding of thermoplastic and ceramic: an experimental investigation, Mater. Manuf. Process. 30 (2015) 1138-1145.

[10] K. Tamrin, S. Zakariyah, N. Sheikh, Multi-criteria optimization in CO 2 laser ablation of multimode polymer waveguides, Opt. Lasers Eng. 75 (2015) 48-56.

[11] K. Tamrin, S. Zakariyah, K. Hossain, N. Sheikh, Experiment and prediction of ablation depth in excimer laser micromachining of optical polymer waveguides, Adv. Mater. Sci. Eng. 2018 (2018).

[12] S.S. Zakariyah, P.P. Conway, D.A. Hutt, D.R. Selviah, K. Wang, J. Rygate, J. Calver, W. Kandulski, Fabrication of polymer waveguides by laser ablation using a $355 \mathrm{~nm}$ wavelength Nd: YAG laser, J. Lightwave Technol. 29 (2011) 3566-3576.

[13] K. Tamrin, Y. Nukman, I. Choudhury, S. Shirley, Multiple-objective optimization in laser cutting of different thermoplastics, Opt. Lasers Eng. 67 (2014) 57-65.

[14] I. Choudhury, P. Chuan, Experimental evaluation of laser cut quality of glass fibre reinforced plastic composite, Opt. Lasers Eng. 51 (2013) 1125-1132.

[15] I. Choudhury, S. Shirley, Laser cutting of polymeric materials: an experimental investigation, Opt. Laser Technol. 42 (2010) 503-508.

[16] I. Choudhury, W. Chong, G. Vahid, Hole qualities in laser trepanning of polymeric materials, Opt. Lasers Eng. 50 (2012) 1297-1305.

[17] M. Imran, P. Mativenga, A. Gholinia, P. Withers, Assessment of surface integrity of Ni superalloy after electrical-discharge, laser and mechanical micro-drilling processes, Int. J. Adv. Manuf. Technol. 79 (2015) 1303-1311.

[18] H. Sezer, L. Li, M. Schmidt, A. Pinkerton, B. Anderson, P. Williams, Effect of beam angle on HAZ, recast and oxide layer characteristics in laser drilling of TBC nickel superalloys, Int. J. Mach. Tools Manuf. 46 (2006) 1972-1982.

[19] R.S. Bunker, A review of shaped hole turbine film-cooling technology, J. Heat Transf. 127 (2005) 441-453.

[20] L. Romoli, F. Fischer, R. Kling, A study on UV laser drilling of PEEK reinforced with carbon fibers, Opt. Lasers Eng. 50 (2012) 449-457. 
[21] L. Romoli, C. Rashed, G. Lovicu, G. Dini, F. Tantussi, F. Fuso, M. Fiaschi, Ultrashort pulsed laser drilling and surface structuring of microholes in stainless steels, CIRP Ann. 63 (2014) 229-232.

[22] S. Aoyagi, H. Izumi, Y. Isono, M. Fukuda, H. Ogawa, Laser fabrication of high aspect ratio thin holes on biodegradable polymer and its application to a microneedle, Sensors Actuators A Phys. 139 (2007) 293-302.

[23] J. Oh, K. Liu, T. Medina, F. Kralick, H.M. Noh, A novel microneedle array for the treatment of hydrocephalus, Microsyst. Technol. 20 (2014) 1169-1179.

[24] H. Hocheng, C. Tsao, The path towards delamination-free drilling of composite materials, J. Mater. Process. Technol. 167 (2005) 251-264.

[25] F. Makhdum, V.A. Phadnis, A. Roy, V.V. Silberschmidt, Effect of ultrasonically-assisted drilling on carbon-fibre-reinforced plastics, J. Sound Vib. 333 (2014) 5939-5952.

[26] D. Herzog, P. Jaeschke, O. Meier, H. Haferkamp, Investigations on the thermal effect caused by laser cutting with respect to static strength of CFRP, Int. J. Mach. Tools Manuf. 48 (2008) 1464-1473.

[27] R. Biswas, A. Kuar, S. Sarkar, S. Mitra, A parametric study of pulsed Nd: YAG laser micro-drilling of gamma-titanium aluminide, Opt. Laser Technol. 42 (2010) 23-31.

[28] M. Hanon, E. Akman, B.G. Oztoprak, M. Gunes, Z. Taha, K. Hajim, E. Kacar, O. Gundogdu, A. Demir, Experimental and theoretical investigation of the drilling of alumina ceramic using Nd: YAG pulsed laser, Opt. Laser Technol. 44 (2012) 913-922.

[29] A. Ancona, F. Röser, K. Rademaker, J. Limpert, S. Nolte, A. Tünnermann, High speed laser drilling of metals using a high repetition rate, high average power ultrafast fiber CPA system, Opt. Express 16 (2008) 8958-8968.

[30] W. Li, R. Zhang, Y. Liu, C. Wang, J. Wang, X. Yang, L. Cheng, Effect of different parameters on machining of $\mathrm{SiC} / \mathrm{SiC}$ composites via pico-second laser, Appl. Surf. Sci. 364 (2016) 378-387.

[31] F. Al-Sulaiman, B. Yilbas, M. Ahsan, CO 2 laser cutting of a carbon/carbon multilamelled plain-weave structure, J. Mater. Process. Technol. 173 (2006) 345-351.

[32] J. Mathew, G. Goswami, N. Ramakrishnan, N. Naik, Parametric studies on pulsed Nd: YAG laser cutting of carbon fibre reinforced plastic composites, J. Mater. Process. Technol. 89 (1999) 198-203.

[33] A. Salama, L. Li, P. Mativenga, A. Sabli, High-power picosecond laser drilling/machining of carbon fibre-reinforced polymer (CFRP) composites, Appl. Phys. A 122 (2016) 73.

[34] M. Okasha, P. Mativenga, N. Driver, L. Li, Sequential laser and mechanical micro-drilling of Ni superalloy for aerospace application, CIRP Ann. 59 (2010) 199-202.

[35] K. Voisey, S. Fouquet, D. Roy, T. Clyne, Fibre swelling during laser drilling of carbon fibre composites, Opt. Lasers Eng. 44 (2006) 1185-1197.

[36] W. Rodden, S. Kudesia, D. Hand, J. Jones, A comprehensive study of the long pulse Nd: YAG laser drilling of multi-layer carbon fibre composites, Opt. Commun. 210 (2002) 319-328.

[37] P. Moreno, C. Méndez, A. García, I. Arias, L. Roso, Femtosecond laser ablation of carbon reinforced polymers, Appl. Surf. Sci. 252 (2006) 4110-4119.

[38] Z. Li, H. Zheng, G. Lim, P. Chu, L. Li, Study on UV laser machining quality of carbon fibre reinforced composites, Compos. A: Appl. Sci. Manuf. 41 (2010) 1403-1408.

[39] O. Yalukova, I. Sarady, Investigation of interaction mechanisms in laser drilling of thermoplastic and thermoset polymers using different wavelengths, Compos. Sci. Technol. 66 (2006) 1289-1296.

[40] N. Ren, L. Jiang, D. Liu, L. Lv, Q. Wang, Comparison of the simulation and experimental of hole characteristics during nanosecond-pulsed laser drilling of thin titanium sheets, Int. J. Adv. Manuf. Technol. 76 (2015) 735-743. 
[41] F. Brandi, N. Burdet, R. Carzino, A. Diaspro, Very large spot size effect in nanosecond laser drilling efficiency of silicon, Opt. Express 18 (2010) 23488-23494.

[42] T. Canel, A.U. Kaya, B. Celik, Parameter optimization of nanosecond laser for microdrilling on PVC by Taguchi method, Opt. Laser Technol. 44 (2012) 2347-2353.

[43] W. Hu, Y.C. Shin, G.B. King, Micromachining of metals, alloys, and ceramics by picosecond laser ablation, J. Manuf. Sci. Eng. 132 (2010) 011009.

[44] A. Spiro, M. Lowe, G. Pasmanik, Drilling rate of five metals with picosecond laser pulses at 355, 532, and $1064 \mathrm{~nm}$, Appl. Phys. A 107 (2012) 801-808.

[45] N. Muhammad, D. Whitehead, A. Boor, W. Oppenlander, Z. Liu, L. Li, Picosecond laser micromachining of nitinol and platinum-iridium alloy for coronary stent applications, Appl. Phys. A 106 (2012) 607-617.

[46] Y. Liu, C. Wang, W. Li, L. Zhang, X. Yang, G. Cheng, Q. Zhang, Effect of energy density and feeding speed on micro-hole drilling in $\mathrm{C} / \mathrm{SiC}$ composites by picosecond laser, J. Mater. Process. Technol. 214 (2014) 3131-3140.

[47] R. Zhang, W. Li, Y. Liu, C. Wang, J. Wang, X. Yang, L. Cheng, Machining parameter optimization of $\mathrm{C} / \mathrm{SiC}$ composites using high power picosecond laser, Appl. Surf. Sci. 330 (2015) 321-331.

[48] C. Wang, L. Zhang, Y. Liu, G. Cheng, Q. Zhang, K. Hua, Ultra-short pulse laser deep drilling of C/SiC composites in air, Appl. Phys. A 111 (2013) 1213-1219.

[49] N. Krstulović, S. Shannon, R. Stefanuik, C. Fanara, Underwater-laser drilling of aluminum, Int. J. Adv. Manuf. Technol. 69 (2013) 1765-1773.

[50] A. Nath, D. Hansdah, S. Roy, A.R. Choudhury, A study on laser drilling of thin steel sheet in air and underwater, J. Appl. Phys. 107 (2010) 123103.

[51] N. Iwatani, H.D. Doan, K. Fushinobu, Optimization of near-infrared laser drilling of silicon carbide under water, Int. J. Heat Mass Transf. 71 (2014) 515-520.

[52] Y. Yan, L. Li, K. Sezer, W. Wang, D. Whitehead, L. Ji, Y. Bao, Y. Jiang, CO 2 laser underwater machining of deep cavities in alumina, J. Eur. Ceram. Soc. 31 (2011) 2793-2807. 